\title{
$\operatorname{arCOS} D E S I G N$
}

\section{Queerizar o Design}

\section{Denise Portinari (PUC-Rio, Brasil)}

denisep@puc-rio.br

Pontifícia Universidade Católica do Rio de Janeiro

Rua Marquês de São Vicente, número 225 - Gávea, Rio de Janeiro - RJ 


\section{Queerizar o Design}

Resumo: Este artigo propõe pensar o design a partir de uma perspectiva queer, enfatizando o aspecto agencial do termo queer. "Queerizar" o design seria sensibilizar o campo para os aspectos e os efeitos políticos, éticos, estéticos e subjetivos do design na contemporaneidade, abordando-o enquanto processo social de configuração do sensível compartilhado, do espaço comum. É ainda problematizar e transviar a participação do design na (re)produção e materialização das estratégias da normatividade, através da análise crítica de sua inserção nesses processos, agenciando-o para a produção de perspectivas e práticas contra-normativas e a potencialização de novas possibilidades de existência. Essa proposta é desenvolvida através de uma discussão dos modos de agenciamento queer e dos modos de participação do design na materialização de performatividades normativas.

Palavras-chave: Queer, Design, Normatividade

\section{Queering Design}

Abstract: This paper argues for bringing a queer perscpective to design theories, methodologies and practices. The word "queer" is used here mainly as a verb, in order to emphasize its aspect as a critical practice of appropriation, re-signification and deconstruction of normativity. The proposed argument is developed through a discussion of queer theorizations and practices, and of the role played by design in the materialization of normatized forms of embodiment and subjectivity. Design is examined here in its triple insertion in the production of industrialized artifacts and communication systems, in the configuration of common spaces and sensibilities, and in design education and research, which seem to mutually reinforce its normative potentialities. Queering design is proposed as a way of sensitizing design theories and practices to the political, ethical, aesthetical and subjective aspects of design in contemporary society.

Keywords: Queer, Design, (Hetero)Normativity 


\section{Introdução}

Este artigo propõe uma articulação entre o design e a teoria queer ${ }^{1}$. Mais precisamente, propõe pensar alguns aspectos da prática e da pesquisa em design a partir de uma perspectiva queer. Essa perspectiva não se limita ao âmbito das questões e lutas LGBT , mas parte delas para problematizar a (hetero)normatividade e a produção/materialização normativa de identidades, subjetividades e diferenças sociais, potencializando a proposição de novas possibilidades de existência.

Nesse sentido adotamos aqui a forma verbal do termo queer, ampliando assim o seu escopo e enfatizando o seu aspecto agencial: queerizar o design, é agenciá-lo para a problematização da normatividade e de suas materializações, inclusive aquelas que estão presentes em suas teorizações, metodologias e práticas. (RUSSELL, SARICK, \& KENNELLY, J. 2002, p.54).

Queerizar o design seria portanto sensibilizar o campo para os aspectos e os efeitos políticos, éticos, estéticos e subjetivos do design na contemporaneidade, abordando-o enquanto processo social de configuração do sensível compartilhado, do espaço comum . Queerizar é ainda problematizar e transviar a participação do design na (re)produção e materialização das estratégias da normatividade, através da análise crítica de sua inserção nesses processos, agenciando-o para a produção de perspectivas e práticas contra-normativas e a potencialização de novas possibilidades de existência.

Todavia cabe lembrar que o design não é uno, e que seu campo se constitui em um entrecruzamento de diferentes práticas e espaços. Se falamos aqui de "um" design , é apenas no sentido de uma certa genealogia e de uma inserção social mais ou menos compartilhada por essas diferentes instâncias. Da mesma forma, não se poderia concebê-lo como um processo projetual "puro" cujas implicacões políticas e sociais dependeriam apenas dos meios e dos modos de sua instrumentalização, ou do seu "bom uso".

Portanto não se trata de propor uma transformação do design (que não é uno) pelo queer (que também não é um campo unificado), em uma abordagem totalizante que não poderia ser mais anti-queer. Trata-se antes de propor a abertura e a potencialização de questionamentos, brechas, linhas de fuga e contaminações. As estratégias, problematizações e (contra)metodologias queer tem atuado em diferentes áreas para promover

\footnotetext{
${ }^{1}$ Este artigo foi desenvolvido a partir do convite, feito pelo evento Design.com: Articulações, Expansões e Conexões, para apresentar um trabalho na mesa Articulações do Design: Uma Ecologia dos Saberes.
} 
práticas mais fluídas, borrar fronteiras disciplinares e introduzir na pesquisa acadêmica novas possibilidades de pensamento e de ação. Por outro lado, a perspectiva e os instrumentos do design, especialmente no que concerne o seu papel na materialização de imaginários, políticas, sensibilidades e relações sociais, podem trazer novas possibilidades de problematização e de agenciamento queer.

Ao longo deste artigo, procuramos desenvolver essa proposta através da exploração das práticas e teorizações queer, da problematização das orientações e práticas (hetero)normativas do design, e da proposição de formas de seu agenciamento na queerização da normatividade e na potencialização das diferenças. O design pode ser queerizado - sempre no varejo, pontualmente, fragmentariamente e capilarmente- mas sempre na medida em que também pode queerizar.

\section{2. $O$ agenciamento queer}

O termo queer, em inglês, tem os significados de estranho, desviado, anormal, ou esquisito, e é especialmente utilizado para designar indivíduos de gêneros e orientações sexuais consideradas como desviantes em relação à norma ou à (hetero)normatividade. Apropriado por dissidentes dos movimentos LGBT da década de 80 (notadamente pelo grupo ACT UP), o termo é ressignificado como uma forma de (ex)istir e de resistir aos imperativos e às políticas (hetero)normativas.

(Ex)istir na medida em que o queer, nessa nova acepção, passa a designar não mais uma identidade, mas antes uma posição, um lugar, uma certa maneira de problematizar, de posicionar-se e de agir em relação à normalidade e à norma. Assim, o queer não é empregado aqui como um termo guarda-chuva que cobriria diferentes identidades sexuais e de gênero (LGBT e outras), nem como mais uma dessas formas identitárias, mas antes como uma maneira de questionar e de subverter os dispositivos produtores de subjetividades normatizadas e portanto também a própria noção essencialista de identidade. Se é possível falar em uma identidade queer, é apenas no sentido da "manutenção de uma função, como lugar vazio de uma identidade jamais realizada e sempre em devir". (HALPERIN, 2000, p. 123)

Além de constituir uma política, uma ética e uma estética contranormativas, o queer é também um instrumental de investigação e problematização crítica da (hetero)normatividade, ou uma analítica da normatividade, avançada nas teorizações queer.

A teoria queer começa de certa forma nas ruas, com a queerização do ativismo político gay e lésbico norte-americano, espaços em que o termo 
queer emerge como forma de problematização radical da normatividade a partir da ocupação estratégica de um lugar de abjeção, e como forma de potencialização crítica da diferença, para além das políticas identitárias da tolerância e da assimilação. Disseminada nos espaços universitários, essa forma de problematização/ politização da normatividade e de potencialização crítica da diferença inscreve-se no cerne das teorizações queer, constituindo ao mesmo tempo o seu método de pesquisa e o seu campo de ação. (PORTINARI \& CESAR, 2017)

Assim, a teoria queer começa também nas universidades, ficando conhecida através de conferências promovidas por instituições "Ivy League" nos EUA. (MISKOLCI, 2009) Há um certo consenso de que a circulação acadêmica do termo foi inaugurada em 1990 pela estudiosa feminista Teresa de Lauretis, em uma conferência na Universidade da Califórnia. A teorização queer logo passa a abranger um corpo relativamente heterogêneo de publicações de autores seminais como Judith Butler, Jack Halberstein, Eve Kosofsky Sedgwick, José Esteban Muñoz, Lauren Beriant, Lee Edelman, David Halperin e Gayle Rubin, entre outros.

Cabe lembrar ainda que a teoria queer é desenvolvida em espaços acadêmicos ocupados pelos estudos culturais, feministas, gays e lésbicos ou seja, em espaços já marcados por uma história de enraizamento e interlocuções com os movimentos políticos.

Simultaneamente, a convergência dos estudos queer e feministas com a vertente pós-colonial dos estudos culturais fez reverberar os questionamentos trazidos do interior dos movimentos políticos identitários pelas reivindicações de sujeitos que não se sentiam ali representados. Essa sintonia irá potencializar as abordagems interseccionais ou consubtanciais que enfatizam a interdependência das relações de poder de gênero, sexualidade, raça e classe.

A trasladação do queer das ruas para o mundo acadêmico (e para uma certa "elite" desse mundo), gera novas questões e tensões entre os movimentos sociais e a universidade, produzindo ao mesmo tempo novas potencializações do queer mas também novos riscos de assimilação e de perda de seu potencial crítico.

Intelectualmente e "espiritualmente", como aponta Halperin (2000), a teoria queer é disparada pelo encontro dos estudos feministas, gays e lésbicos com o pensamento de Michel Foucault. Segundo Spargo, Foucault não é o ponto de "origem" da teoria queer, e esta não é o "ponto de destinação" do pensamento foucaultiano; entretanto, Foucault "pode ser entendido como um catalisador, um ponto de partida, um exemplo e antecedente mas também como um agente de irritação permanente, um 
estopim que continuamente provoca a produção de novas ideias" (SPARGO, 1999, p.10).

Segundo a hipótese repressiva, em sua versão mais amplamente difundida, a sexualidade originariamente "livre", entendida como expressão mais ou menos "natural" de forças instituais e sede da verdade mais profunda do sujeito, vem a ser silenciada, proibida e deformada/recalcada pela hegemonização da ideologia burguesa entrelaçada às exigências do desenvolvimento da sociedade industrial em um modo de produção capitalista. Em seu exame da época vitoriana que epitomizaria tal processo, Foucault problematiza irreversivelmente essa visão ao mostrar que a sexualidade "reprimida", é ela própria, o efeito de uma forma moderna de exercício do poder que não se caracteriza tanto pela negatividade da interdição quanto pela positividade da "produção". A época vitoriana, longe de constituir o cenário de uma sexualidade finalmente silenciada e proibida, aparece como o espaço em que a sexualidade é incessantemente produzida através de uma "proliferação inaudita" de discursos, práticas, saberes e estratégias que são "heterogêneas entre si" mas que tem o efeito comum de constituir, esquadrinhar e multiplicar formas de sexualidade tornadas também "formas de subjetividades", como parte de uma nova estratégia de normatização. A essa máquina de produção da sexualidade como forma de subjetividade e da verdade mais profunda do sujeito, Foucault dará o nome de "dispositivo da sexualidade". Entre os seus efeitos está a proliferação de sexualidades "perversas" e sua transformacão em formas de subjetividades "anormais" ou patologizadas que constituem um marcador em relação ao qual as subjetividades "normais" são também constituídas. O dispositivo da sexualidade agencia assim a produção das subjetividades "homossexual" e "heterosexual" como formas de identidade e de verdade fundamental dos indivíduos.

Foucault assinala, em uma passagem amplamente conhecida da Vontade de Saber, o aparecimento no século XIX do termo "homossexual", para designar um novo tipo de sujeito. Até então a homossexualidade havia sido considerada principalmente como uma prática, sintetizada juridicamente na figura da sodomia - na maior parte dos casos severamente condenada - mas de que todos seriam potencialmente suscetíveis, assim como todos seriam em princípio suscetíveis ao pecado ou ao crime. A figura do "homossexual" já não irá se referir apenas ao sujeito (jurídico) de uma prática, mas antes a uma forma específica de subjetividade, um certo modo de ser e de conduzir-se, uma forma de sensibilidade, um modo de "inverter, em si mesmo, o masculino e o feminino". Se antes o sodomita era um reincidente, doravante o homossexual será um personagem. (FOUCAULT, 1984, p.44) 
A Vontade de Saber propõe assim uma concepção nova do poder e de suas formas de atuação; o poder não é propriedade de um grupo ou de uma instância que o exerceria sobre outros grupos e instâncias; o poder está em toda parte, e é antes o efeito das relações entre os atores sociais do que o apanágio destes ou daqueles. Junto com isso, o poder moderno não se caracteriza prioritariamente pela repressão ou pela interdição - ainda que sempre presentes - e sim pela produção e multiplicação de linhas de penetração, em que finalmente nada escapa às suas malhas. A sexualidade, ao invés de constituir uma essência que em certa medida lhe escaparia ou que antecederia o exercício de um poder que viria abafá-la, é ela própria um efeito do dispositivo do poder que a constitui.

Essa concepção será uma das inspirações principais entre as que deflagram os movimentos queer e sua atuações políticas na década de 80. Já não se tratará então de privilegiar um discurso de "liberação" das sexualidades ou da "inclusão" de suas formas consideradas como anormais ou desviantes - principais reivindicacões dos movimentos gays e lésbicos até então - mas antes da apropriação do lugar de abjeção conferido a essas formas, transformando-o em um lugar de resistência a todas as formas de normatização, e de invenção e potencialização de novas formas de existência e de relações - afetivas, eróticas, existenciais e políticas.

No Brasil, a introdução da teorização queer nos espaços acadêmicos deu-se através da confluência dos estudos foucaultianos, feministas e culturais especialmente no âmbito da educação, marcado pelos textos de Guacira Lopes Louro sobre o potencial critico das políticas queer:

Queer pode ser traduzido por estranho, talvez ridículo, excêntrico, raro, extraordinário. Mas a expressão também se constitui na forma pejorativa com que são designados homens e mulheres homossexuais. Um insulto que tem, para usar o argumento de Judith Butler, a força de uma invocação sempre repetida, um insulto que ecoa e reitera os gritos de muitos grupos homófobos, ao longo do tempo, e que, por isso, adquire força, conferindo um lugar discriminado e abjeto àqueles a quem é dirigido. Este termo, com toda sua carga de estranheza e de deboche, é assumido por uma vertente dos movimentos homossexuais precisamente para caracterizar sua perspectiva de oposição e de contestação. Para esse grupo, queer significa colocar-se contra a normalização - venha ela de onde vier. Seu alvo mais imediato de oposição é, certamente, a heteronormatividade compulsória da sociedade; mas não escaparia de sua crítica a normalização e a estabilidade propostas pela política de identidade do movimento homossexual dominante. Queer representa claramente a diferença que não quer ser assimilada ou tolerada e, portanto, sua forma de ação é muito mais transgressiva e perturbadora. (LOURO, 2001, p.546) 
A autora, assim como outros teóricos e teóricas queer, propõe o termo sobretudo como verbo, ou seja como uma forma de agenciamento que abrange a própria ação teórica e metodológica. Queer como verbo é mais do que estranhar, é produzir o estranhamento. No vernáculo, “queerizar" ( to queer) é desviar, entortar, desconfigurar, transmutar, tornar estranho o que parecia familiar. É muito mais uma atividade crítica do que uma metodologia, mas pode ser explorada em seu potencial (contra)metodológico, especialmente no âmbito da pesquisa acadêmica. Uma metodologia queer constitui-se a partir da fluidificação e subversão das fronteiras e metodologias disciplinares convencionais, como observa Judith Halberstam:

Uma metodologia queer é, de certa forma, uma metodologia rapinante que utiliza diferentes métodos para coletar e produzir informações sobre assuntos e sujeitos que foram deliberadamente ou acidentalmente excluídos dos estudos tradicionais sobre o comportamento humano. A metodologia queer procura combinar métodos que são frequentemente considerados como incompatíveis entre si, e recusa a compulsão acadêmica pela coerência disciplinar. (HALBERSTAM, 1998, p.19)

Mais radicalmente, podemos dizer que uma metodologia queer seria quase um contra-senso, e que só pode constituir-se ao jogar com esse contra-senso, considerando que "tanto para a academia como para os ativistas, o queer alcança o seu potencial crítico definindo-se a si mesmo face ao normal, mais do que ao heterossexual, e o normal inclui o exercício acadêmico". (MUÑOZ, 2005, p. 198)

Assim, queerizar constitui antes uma forma de subverter a normatividade, inclusive a normatividade da produção acadêmica, do que um instrumento metodológico. De fato, a teorização queer exerce mais agudamente o seu potencial crítico na vertente "negativizante" nominada por Halberstam como a "virada anti-social" nos estudos queer, avançada por autores como Leo Bersani, Lee Edelman e o/a próprio/a Halberstam:

Trabalhos recentes da teoria queer, sob a influência da definição proposta por Leo Bersani - do sexo como anti-comunitário, autofragmentador e anti-identitário, produzem uma virada contra-intuitiva mas crucial que lança o pensamento na contra-mão dos projetos de redenção, reconstrução, restauração e resgate e na direção daquilo que só pode ser chamado de uma teoria anti-social, negativa e anti-relacional da sexualidade (...) Quanto ao alcance político do projeto de Bersani, na medida em que se pode identificar uma trajetória política no âmbito de um projeto radicalmente não-teleológico, ele reside na rejeição brutal das platitudes reconfortantes de que lançamos mão para amortecer a nossa queda na mortalidade, na incoerência e não-dominância. (HALBERTSAM, 2008, p. 140) 
Entre os trabalhos situados nessa vertente, vale lembrar a análise avançada por Lee Edelman, que situa o queer como contraponto de resistência radical ao futurismo e à figura mítica da criança, alçada a encarnação máxima das aspirações burguesas de reprodução, progresso e continuidade no futuro. $O$ sujeito queer, ele argumenta, tem sido epistemologicamente vinculado à negatividade, ao não-senso, à antiprodutividade e a ininteligibilidade. Assim, ao invés de lutar contra essa caracterização e em favor do reconhecimento, mais vale abraçar essa negatividade e assumir a função de um limite e uma força contrária à futuridade, às políticas progressistas, reprodutivas e heteronormativas que animam tantos projetos políticos atuais. (EDELMAN, )

Sendo assim, faz algum sentido pensar em uma articulação entre o queer - em sua potência crítica de desconstrução - e o design, enquanto campo fundamentalmente vinculado a um projeto construtivo e aos seus efeitos normatizantes?

Para discutir essa questão, vamos examinar as afirmativas avançadas acima, sobre o papel construtivo e normatizador do design tomado como processo social.

\section{Design e Normatividade}

Em Objetos do Desejo, Adrian Forty (2007) desenvolve uma crítica ao paradigma do "bom design" - concepção essencialista do design entendido como método "puro", a-histórico, não-contingente de produção de bens materiais - e propõe pensar o design como processo social. Segundo ele, ao pensarmos o design como um processo social voltado para a produção de bens e serviços, somos levados a considerar também a sua atuação na materialização de ideologias, imaginários e relações sociais.

A abordagem de Forty desenvolve-se através de uma análise histórica, social, econômica e política das diversas atividades envolvidas na produção de artefatos materiais na sociedade industrial, considerando que "o design nasceu em um determinado estágio da história do capitalismo e desempenhou papel vital na criação da riqueza industrial”. (2007, p.11)

O papel desempenhado pelo design na criação dos artefatos materiais da sociedade industrial (e, poderíamos acrescentar, de seus sistemas de comunicação, serviços e bens ditos "imateriais" - ainda que essa qualificação seja bastante discutível) está associado, como veremos mais adiante, à sua participação naquilo que Rancière (2012) identificará como o regime estético predominante na contemporaneidade, que organiza certas 
forma de habitação do mundo sensível, certas formas do pensável e do visível.

Para Forty, "o design é uma atividade mais significativa do que se costuma reconhecer, especialmente em seus aspectos econômicos e ideológicos."

Segundo ele, um aspecto crucial, ligado ao papel econômico, é a influência do design em nossa forma de pensar. de perceber e de vivenciar o mundo:

Aqueles que se queixam dos efeitos da televisão, do jornalismo, da propaganda e da ficção sobre nossa mente esquecem a influência similar exercida pelo design. Longe de ser uma atividade artística neutra e inofensiva, o design, por sua própria natureza, provoca efeitos muito mais duradouros do que os produtos efêmeros da mídia porque pode dar formas mais tangíveis e permanentes às idéias sobre quem somos e como devemos nos comportar. (FORTY, 2007, p. 12)

O papel desempenhado pelo design na materialização das idéias, normas e valores da sociedade é evideciado por Forty em uma série de estudos, entre os quais destacamos aquele voltado para a participação do design na materialização das diferenças de gênero, idade e classe social.

Através da análise de diferentes objetos - como os catálogos de venda postal de bens de consumo na virada do século XX, a produção de mobiliários e decorações destinados a configurar o novo espaço caseiro do "quarto das crianças" no século XIX, e os processos de padronagem de tecidos para a produção de peças de vestuário destinados ao consumo de diferentes classes sociais - evidenciam-se os modos de categorizar, de "encarnar" e de naturalizar as diferenças entre homens e mulheres, adultos e crianças, patrões e empregados.

Essas categorias são ao mesmo tempo postuladas e materializadas em atributos como a ornamentação sinuosa, a delicadeza e a relativa fragilidade dos canivetes destinados ao publico feminino, em contraste com as linhas retas, a robustez e a sobriedade dos canivetes masculinos. Da mesma maneira, cria-se todo um imaginário de cores pastéis, animais antropomorfizados e especificações medico-pedagógicas para a caracterização e delimitacão das subjetividades e dos espaços infantis. A precariedade dos materiais, a feiura desconfortável do mobiliário destinado ao aposento dos criados serve ao mesmo tempo para circunscrever e para reafirmar toda a distância dos padrões de sensibilidades e de necessidades atribuídas respectivamente aos empregados e aos seus patrões. 
Terry Eagleton, em Ideologia da Estética (1993), apresenta a estética como dimensão privilegiada do modo de vida e da ideologia burguesa. Ele emprega "ideologia" no sentido gramsciano de hegemonia, propondo pensar a hegemonia da classe media como o projeto que move a estética desde a Inglaterra seiscentista até a contemporaneidade, como um projeto de estetização do poder. A dimensão estética da existência configura-se, no advento da sociedade industrial e de sua nova classe dominante, como espaço de materialização e de reafirmação das relações sociais e dos valores, hábitos, crenças e sensibilidades que constituem o modo de funcionamento de uma nova forma de regulação da coesão social, movida sobretudo pelo agenciamento assujeitador e internalizado da norma, em contraste com a exterioridade coercitiva do aparato absolutista:

A última força de coesão da ordem social burguesa, em contraste com o aparato coercitivo do absolutismo, serão os hábitos, as devoções, os sentimentos e os afetos. Isso equivale a dizer que o poder, neste regime, foi estetizado. Ele é indissociável dos impulsos espontâneos do corpo, está imbricado às sensibilidades e aos afetos, é vivido como costume irrefletido. O poder está agora inscrito nas minúcias da experiência subjetiva, e a fissura entre o dever abstrato e a inclinação prazeirosa foi curada. Dissolver as leis nos costumes, no simples hábito impensado, é identificá-las ao próprio bemestar do sujeito, de modo que trangredi-las significaria uma profunda autoviolência. $\mathrm{O}$ novo sujeito, que doa a si mesmo, a partir de si mesmo, uma lei indissociável de sua experiência imediata, encontrando sua liberdade na necessidade, é modelado no objeto estético. (EAGLETON, 1993, p.22)

Ao mesmo tempo, esse projeto é caracterizado por Eagleton como profundamente ambivalente, na medida em que "um novo tipo de indivíduo - sensível, apaixonado, individualista - coloca um desafio ideológico à ordem dominante, produzindo novas dimensões de sentimento para além dos limites propostos por ela".

É na vigência desse projeto e de seus efeitos ambíguos que o design se constitui, como processo social de produção de bens de consumo, sistemas de comunicacão e serviços, e também de materialização (estetização) de corpos e subjetividades, de hábitos, sensibilidades, valores e afetos.

Ranciére nos traz uma nova inflexão a essa perspectiva ao propor que o design participa da constituição de um novo regime de partilhas do espaço comum, de configurações do visível e do pensável, de certas formas de habitação do mundo sensível, que ele chama de "regime estético". Seu questionamento incide sobre o modo como as práticas e as idéias do design, tal como se desenvolvem a partir início do século XX, participam da 
redefinição do lugar das atividades de arte no conjunto das práticas que configuram o mundo sensível compartilhado.

O que me interessa é o modo como, traçando linhas, dispondo palavras ou repartindo superfícies, desenham-se também partilhas do espaço comum. A maneira como, reunindo palavras ou formas, definem-se não só formas de arte mas ainda certas configurações do visível e do pensável, certas formas de habitação do mundo sensível. Essas configurações, que são ao mesmo tempo simbólicas e materiais, atravessam as fronteiras entre as artes, os gêneros e as épocas. Atravessam as categorias de uma história autônoma da técnica, da arte ou da política. Será deste ponto de vista que abordarei a questão: como a prática e a ideia do design, o modo como se desenvolvem no início do século XX, redefinem o lugar das atividades da arte no conjunto de práticas que configuram o mundo sensível compartilhado - a prática dos criadores de mercadorias, dos que as dispõem nas vitrines ou colocam suas imagens em catálogos, dos construtores de prédios ou de cartazes, que edificam o "mobiliário urba no" ; mas também dos políticos que propõem novas formas de comunidade em torno de certas instituições, práticas ou equipamentos exemplares, por exemplo, a eletricidade e os sovietes. (RANCIERE, 2012, p. 101)

Essa questão é conduzida por ele sob a forma de uma comparação à primeira vista improvável, entre o poeta Mallarmé e o engenheiro-arquiteto e designer Peter Behrens. Interessa sobretudo a Ranciere, neste exercício, a questão do papel desempenhado aí pelo ideário do movimento Arts \& Crafts, que ele detecta presente ainda nas propostas de Behrens em sua confluência com as de Mallarmé: a mesma idéia das formas simplificadas e a mesma função atribuída a essas formas: definir uma nova textura da vida comum.

A ambiguidade desse projeto, no que concerne o design, é assinalada por Rancière nas difererentes apropriações a que se prestamaram as propostas do Arts \& Crafts:

Nós nos indagamos então como essa ideologia passeista, neogótica e espiritualista pôde alimentar em William Morris uma idéia de socialism e um engajamento socialista que não é um simples entusiasmo de esteta, mas uma prática militante presente no campo das lutas sociais? Como pôde essa idéia, passando da Inglaterra para a Alemanha, tornar-se a ideologia modernista-funcionalista do Werkbund e da Bauhaus, e, no caso de Behrens, se transformer na ideologia de uma engenharia functional, posta a serviço de um cartel industrial? (RANCIËRE, 2012, p. 111)

A primeira resposta, lembra ele, consistiria em dizer que uma ideologia é apenas o véu de outra ideologia: "os devaneios do artista 
reconciliado coma bela obra e a fé coletiva de outrora (Arts \& Crafts) seriam a mistificação espiritualista apropriada para seconder uma realidade totalmente contrária, uma submissão aos princípios da racionalidade capitalista". Todavia, "ao invés de opor realidade e ilusão, mistificacão e ua verdade", Rancière sugere que seria mais interessante buscar o elemento comum aos "devaneios neogóticos" e ao princípio modernista/produtivista. Esse elemento seria a idéia da reconfiguração de um mundo sensível comum a partir de um trabalho exercido sobre os seus elementos de base.

Vê-se a dificuldade de estabelecer uma linha divisória nítida entre o design pragmático do princípio modernista/produtivista e o design utópico voltado para o bem-estar social: em última análise, ambos compartilham do mesmo projeto fundamental. Assim, o projeto de configuração do espaço comum e os efeitos de materialização de um sensível subjetivizante, normatizador e normatizado permanecem até certo ponto indissociaveis, a despeito das intenções ou dos objetivos diferenciados que norteiam as diferentes propostas do design.

Um bom exemplo disso é a proposta de reconfiguração humanizada dos ambientes de trabalho, examinada por Forty na análise de iniciativas que datam da virada do século XX mas cujo ideário parece mais atual do que nunca nestes tempos de capitalismo "flexivel". Em nome da humanização do ambiente de trabalho, da proposta de torná-lo mais acolhedor, menos severo, ou, contemporaneamente, mais horizontal e menos circunscrito a um determinado local, produz-se uma sempre crescente intensificacão do trabalho - uma ampliação dos seus tempos e espaços e uma demanda sempre aumentada da dedicação e da produtividade do trabalhador - na medida em que essa eficiência aumentada nunca deixa de constituir o objetivo de tais propostas, ainda que em nome de uma transformação "para melhor" das condições de trabalho.

Junto à sua inserção no mercado e nas práticas de configuração do espaço e das sensibilidades comuns, a relativamente recente inserção do design nos espaços universitários de ensino e de pesquisa, ao mesmo tempo em que abriu novas possibilidades de questionamento e de experimentacão, também tem sido marcada por uma certa adesão (inevitável, talvez) aos ditames do mercado, às políticas sociais e educacionais vigentes e aos valores normativos da produtividade e da inovação. Tais enfrentamentos ultrapassam, é claro, o escopo do seu campo, mas a relativa fragilidade da inserção acadêmica do design pode reforçar tanto o seu assujeitamento às pressões da burocratização universitária quanto o seu potencial de indisciplina e de criação. Nesse sentido, também, a queerização do design favorece outras possibilidades, como a potencialização das diferenças, o 
esmaecimento das fronteiras disciplinares, a criação de estratégias (contra)metodológicas e de práticas problematizadoras dos valores normativos - inclusive aqueles que regem a produção acadêmica burocratizada.

\section{Possibilidades e estratégias de um design queer}

Retornamos aqui, portanto, à questão com que encerramos a seção precedente: que sentido pode fazer a proposta de uma articulação entre o design e o queer? Em que sentido se pode falar em uma queerização do design, sem problematizar o seu projeto fundamentalmente construtivo e seus efeitos normatizantes? E ainda, como poderiam ser essas interações, essa "transa-ação" entre design e queer?

Vale reiterar que não poderia tratar-se de uma "aplicação", pela via do design, das teorizações queer, nem de uma proposta de submeter o design a uma espeécie de intervenção queer. Trata-se antes de uma contaminação do design pelo queer e de uma instrumentalização do queer pelo design. Aqui estamos nos apropriando de toda a carga pejorative dessa palavra quando associada ao queer - patologia, peste, ameaça - para ressignificá-la: deixar-se contaminar pelo queer é problematizar a normatividade de dentro, estranhar as suas práticas e os seus efeitos, e inocular ali uma possibilidade de pensar e viver "outramente".

Queerizar é problematizar a normatividade e potencializar a diferença, lá onde elas se produzem: nos dispositivos de saber e de poder, na performatividade dos discursos e das práticas, na materialização e partilha das (in)visibilidades - e nos seus pontos de fragmentação e fissura. Essa problematização se dá de diversas formas, abrindo novas possibilidades de agenciamento crítico.

Halperin enumera algumas estratégias queer que subvertem a partir de dentro a economia política do discurso (hetero)normativo: a apropiação criativa e a ressignificação, a teatralização; o desvelamento e a desmistificação. Ele nos fornece alguns exemplos: por ocasião da difusão midiática de estudos que propunham descobrir as determinações neurológicas da orientação sexual, apareceu em São Francisco uma nova boate gay chamada "Hipotálamo"; em resposta ao número temático da Newsweek sobre "as lésbicas, quem são, como vivem, como reconhecer uma", em cuja capa figurava um casal de mulheres, a revista LGBT Bay Times publicou a capa de uma revista imaginária chamada "Dykeweek", cuja chamada mostrava um casal de homem e mulher e o título: Heteros, quem são, como vivem, etc. (HALPERIN, 2000, pps. 63-66)

Todavia essas estratégias não podem ser "metodologizadas". Elas se manifestam antes como acontecimentos, movidos por um espírito queer de 
resistência, por uma cultura queer de contra-condutas e por uma problematização queer dos discursos e saberes normativos. O queer subverte e expõe a performatividade normativa dos discursos e práticas sociais através de uma performatividade queer.

Talvez um pouco tarde, no apagar das luzes deste artigo, trazemos a noção de "performatividade" cunhada por Judith Butler, para exploras suas possibilidades de articulação com as práticas e pesquisas do design. Essa noção é cunhada pela teórica queer em interlocução com o pensamento de Foucault.

Ao propor o dispositivo da sexualidade como a instância "real" que produz o "imaginário" da sexualidade e do sexo, Foucault inverte o essencialismo do senso comum, em que o sexo seria o fundamento "real" (no sentido de biológico, natural, ou em todo caso, prévio e resistente às operações do social, do simbólico, etc.) de uma sexualidade "construída".

É preciso destacar que a noção de dispositivo não equivale à noção de "construção"; ao contrário, representa uma ultrapassagem desta última. Não se trata, para Foucault, de demonstrar a radicalidade dessa construção (até o sexo é "construído"), pois o que está implicado na noção do dispositivo é a insuficiência da própria noção. O dispositivo não "constrói" a sexualidade; antes, a materializa, a produz, o que é muito diferente.

A ideia de "construção" supõe uma eficácia organizada da dimensão simbólica (do discurso, da lei) que, aplicada aos sujeitos e aos corpos de alguma maneira pré-existentes, "constrói”" esses sujeitos e corpos segundo as suas determinações, de uma vez por todas. Ora, o que a ideia de "dispositivo" implica é a desorganização, a heterogeneidade e a precariedade dos discursos e das práticas que o constituem e cuja eficácia depende inteiramente de uma mobilização contínua e sempre renovada de suas formas de ação (técnicas, estratégias, montagens, disposições). Mais importante ainda, o dispositivo produz a norma ao produzir as suas formas de transgressão, multiplicando assim as suas linhas de penetração.

O dispositivo não é a lei nem a prescrição (digamos: o "projeto"), embora as incorpore; é muito mais eficaz do que estas, na medida em que participa da materialidade dos corpos na qual se enraíza.

Essa ultrapassagem genealógica da ideia de "construção social" da sexualidade será retomada, a partir de outro viés, por Judith Butler (1990), ao propor uma crítica da distinção habitual sexo/gênero, a partir da noção de performatividade. Se o gênero não é simplesmente "atribuído" aos corpos a partir de um registro simbólico capaz em si mesmo de assegurar o êxito dessa operação, mas antes requer uma constante reiteração e materialização nos corpos que ao mesmo tempo apontam para a sua precariedade 
constitutiva, o sexo enquanto suposto reduto último de uma identidade essencial é igualmente precário e sujeito à condição dessa performatização.

Para Butler, “(...) a performatividade deve ser compreendida não como um 'ato' singular ou deliberado, mas ao invés disso, como a prática reiterativa e citacional (em referência a Derrida) pela qual o discurso produz os efeitos que ele nomeia" (BUTLER, 1993, p. 154)

A noção da materialização performativa de corpos, identidades, subjetividades e diferenças sociais serve ao mesmo tempo para problematizar a idéia de "construção" do social, para desvelar a dimensão performativa da norma e para visibilizar os seus agenciamentos criticos embora a crítica não possa se reduzir à sua performatização.

Começamos assima a entrever as possibilidades dessa noção no que concerne a problematização do projeto e dos valores "construtivos" do design. Simultaneamente, a análise do papel desempenhado pelo design em sua tríplice inserção no mercado, nas práticas de configuração do sensível comum e nos dispositivos de saber/poder possibilita uma ampliação de nossa compreensão dos modos capilares de funcionamento da performatividade. Inscrita não somente nos discursos e nos corpos, mas nas suas extensões, aparelhos, e suportes, na performatividade dos espaços comuns, nas relações sociais que sustentam a produção de serviços e bens de consume, nas configurações do visível e do invisível, a performatividade, vista pela perspectiva do design, está em toda parte.

Nestes tempos em que tanto se proclama a crescente "desmaterializacão" do design, na esteira da ideologia de uma sociedade dita "pós-industrial", vale muito a pena voltar a discutir a materialidade inelutável das produções do design, pelo viés de seus efeitos na materialização performativa de corpos, subjetividades, identidades e diferenças sociais normatizadas.

É nesse sentido, e também no sentido de um agenciamento desse potencial performativo na materialização e visibilização de outras formas de existência, que propomos pensar algumas transações e contaminações possíveis entre o design e o queer.

\section{Referências}

BUTLER, Judith. Gender Trouble: Feminism and the Subversion of Identity. New York: Routledge, 1990. 
BUTLER, Judith. Bodies that matter: on the discursive limits of "sex". New York: Routledge, 1993.

CÉSAR, M. R. A.; PORTINARI, Denise. Estudos Culturais e teoria queer: queerizando os estudos culturais e potencializando o queer. Em Estudos Culturais pps. 277300

EAGLETON, Terry. Ideologia da Estética. Rio de Janeiro: Jorge Zahar Ed., 1993

EDELMAN, Lee. No Future - Queer Theory and the Death Drive. Durham and London: Duke University Press, 2004.

FORTY, Adrian. Objetos de Desejo - Design e sociedade desde 1750. São Paulo: Cosac Naify, 2007.

FOUCAULT, Michel. História da sexualidade. A vontade de saber. Vol. I. Rio de Janeiro: Graal, 1984.

HALBERSTAM, Judith., "The Anti-Social Turn in Queer Studies". Graduate Journal of Social Science, Vol. 5 N. 8, 2008 pps. 140-156

. Female Masculinity. Duke University Press, 1998

HALPERIN, David. Saint Foucault. Towards a Gay Hagiography. New York, Oxford: Oxford University Press, 1995.

LOURO, Guacira.Lopes. Um corpo estranho: ensaio sobre sexualidades e teoria queer. Belo Horizonte: Autêntica, 2004.

MISKOLCI, Richard. "A Teoria Queer e a Sociologia: o desafio de uma analítica da normalização". In: Sociologia, Porto Alegre, ano 11, no. 21, jan./jun. 2009, p.150-182.

MUÑOZ, Allfonso Ceballos. "Teoría Rarita”, em CÓRDOBA, David., SAÉZ, Javier., VIDARTE, Paco. (Orgs.) Teória Queer - Politicas bolleras, maricas, trans, mestizas. Barcelona: Ed. Egales, 2005.

RANCIERE, Jacques. O destino das imagens. Rio de Janeiro: Contraponto, 2012. 
RUSSELL, C.L., SARICK, T., KENNELLY, J. 2002, p.54) "Queering Environmental Education". Canadian Journal of Environmental Education, 7(1), Spring 2002, p.54.

SPARGO, Tamsin. Foucault and Queer Theory. N.Y.: Totem Books, 1999. 


\section{Como citar}

PORTINARI, Denise. Queerizar o design. Arcos Design. Rio de Janeiro: PPD ESDI - UERJ. Edição especial Seminário Design.Com, Outubro 2017. pp. 1-19. Disponível em: [http://www.epublicacoes.uerj.br/index.php/

arcosdesign]

DOI 10.12957/arcosdesign.2017.30937

\section{(c) (i) ()}

A Revista Arcos Design está licenciada sob uma licença Creative Commons Atribuição - Não Comercial - Compartilha Igual 3.0 Não Adaptada. 